\title{
Shear in Pacific's Wide Warm Surface Currents
}

\section{Kern E. Kenyon}

4632 North Lane, Del Mar, CA, USA

Correspondence to: Kern E. Kenyon, kernken@aol.com Keywords: Surface Current Dynamics, Horizontal Shear

Received: June 25, 2019 Accepted: August 9, 2019

Published: August 12, 2019

Copyright $\odot 2019$ by author(s) and Scientific Research Publishing Inc.

This work is licensed under the Creative Commons Attribution International License (CC BY 4.0).

http://creativecommons.org/licenses/by/4.0/

\section{(c) (i) Open Access}

\section{ABSTRACT}

Within the two poleward wide warm surface currents that cross mid-latitudes on the eastern sides of the North and South Pacific Oceans, a single prediction is made that they have a horizontal velocity shear such that their mean speeds monotonically increase from east to west. This prediction is inspired mainly by a re-examination of the east/west asymmetric observations previously documented: the longitudinal maximum in sea surface temperature in the eastern parts of both oceans at mid-latitudes is located significantly west of the region of maximum mixed layer depths, which occur in the middle of these currents. Also the application of recent dynamical considerations discussed below stimulated the prediction, which include the application of Bernoulli's law to streamlines in the flows as well as the geostrophic balance in the cross-stream direction. These caused the rethinking of an earlier explanation, which upon reflection now seems less suitable than the present one.

\section{INTRODUCTION}

How can a discussion about the shear in a current take place before the current itself is fully described? What follows is also unexpected from the perspective that the strength of the mean flow is rather weak. This thread of information concerning the wide warm surface currents of the Pacific has been unwinding in fits and starts over a period of more than 40 years. Added on to the strand here for the first time is a theoretical notion that is consistent with knowledge already gained from the available data.

First, in the 1970s a wide warm surface current off California was inferred to exist from a very large body of sea surface temperature data [1]. The inference is on a solid footing because of the millions of individual measurements of surface temperature involved, even though each data point was only recorded to the nearest one degree $\mathrm{F}$ and all of them were only taken at the sea surface. That much by itself was rather unusual.

Merchant ships crossing the North Pacific cool their engines with sea water entering the hull through a pipe, and near the entry the temperature is read and recorded every hour and later sent to a government agency. Eventually, they were averaged from all participating ships by five degree latitude/longitude squares and by one month intervals. In my possession are 30 years of such compilations covering most of 
the North Pacific, which remain unpublished unfortunately. From quite a few individual voyages [2], using more accurate thermometers and more closely spaced measurements, checks on the reality of features deduced from the monthly mean five-degree square climatology have steadily increased my confidence in these features, and their postulated permanence is based on 30 consecutive years of these data.

Of prime interest and forecast from the climatological data mentioned above is the following fact: if a boat or ship leaves the California coast and heads straight west for at least $4000 \mathrm{~km}$, taking a surface temperature measurement every hour, it will be found that the temperature gently rises to a maximum then falls off again. Latitude of the ship's track and the time of the year do not matter. After some years of study, it began to seem self-evident that in order to sustain a longitudinal maximum is sea surface temperature, warm water had to be continually brought into the region from somewhere that was warmer still, because some heat would inevitably leak out into the atmosphere along the way. In other words, a northward flow was suggested by the indirect evidence of the surface temperatures.

\section{BELOW THE SURFACE}

During March and April of 1976 a complete hydrographic section was made along $35 \mathrm{~N}$ from California to Japan [3]. There were 98 total stations, one at each whole degree of longitude. Alternate stations went all the way to the bottom. My interest was mainly in the measurements of temperature and salinity in the upper few hundred meters of the water column. It was found that surrounding the large-scale sea surface temperature maximum in the eastern half of the section was a lens of nearly uniformly warm water, convex side down, with maximum depths of the mixed layer of about $100 \mathrm{~m}$ near the middle of the upside down lens.

Not at all near the middle of the surface layer, but significantly to the west of it, was the maximum sea surface temperature clearly shown in Figs. 6 \& 8 of Ref. [4]. That asymmetry surprised me. To come up with an explanation I first looked at the climatological sea level pressure data, 30 years of which are in my possession. Already known to me was that in the long term mean the location of the North Pacific high pressure center, a permanent atmospheric feature, is near the longitudinal maximum in sea surface temperature at mid-latitudes. If the assumption is accepted that heating from below by the ocean causes high pressure in the atmosphere [5], then in return the air will cool the sea surface causing penetrative convection. Consequently, where the air pressure is the highest one also expects the mixed layer depth to be greatest. However, this logical chain of reasoning may not turn out to be the complete answer to the question at hand. Monthly mean sea level pressures on a diamond grid (alternating five degree squares [6]) are considerably more variable than are the monthly mean sea surface temperatures, producing difficulty in locating the centers of high pressure from month to month.

In addition it should be pointed out that there exists a large-scale longitudinal maximum in sea surface temperature in the eastern South Pacific and that along $28 \mathrm{~S}$ a detailed hydrographic section showed that this temperature maximum was significantly west of the middle of the region of deepest mixed layer depths (compare Figs. $1 \& 4$ of Ref. [7]). Otherwise the South Pacific is data poor by comparison with the North Pacific, and I have not seen any sea level pressure data there.

\section{HORIZONTAL SHEAR}

Another (perhaps better) way to begin an explanation of the east/west asymmetry described above would probably not have occurred without prompting from a recent but simple theoretical development [8]. Acting constantly on the northward flow in the wide warm current in the North Pacific and on the analogous southward flow in the South Pacific is the Coriolis force. Exactly how is that sideways force balanced so that a steady state is preserved? Geostrophy requires a pressure gradient to balance the Coriolis force. What is the nature of the horizontal pressure force?

Suppose Bernoulli's law is introduced along streamlines inside the poleward surface flows as well as a horizontal shear across these flows such that in both currents the speed monotonically increases westward from slow in the east to faster in the west. Then by applying Bernoulli's relation across streamlines the 
pressure will decrease westward. Now there exists the possibility of a geostrophic balance.

\section{DISCUSSION}

Consistent with the above dynamic argument is the fact that the highest sea surface temperatures occur in the western part of the surface layer in both hemispheres, since a faster flow speed would leak less heat to the atmosphere, because of the shorter time available to do it, leading to higher temperatures there.

In summary, with the aid of very many sea surface temperatures, several decades ago a wide warm surface current was inferred to flow northward off the coast of California. To this day direct measurements of the flow speed of this sluggish poleward current have not been made. Now, subsurface temperatures in the surface layer have led to the idea of a horizontal shear in the flow, faster in the west and slower in the east. A dynamical concept also helped to stimulate this proposal of a shear. Hope of measuring the shear in a flow that has not yet itself been directly revealed by observations would seem to be very dim at this point, but if satellite tracking of surface floats placed in the poleward surface flows were carried out, that might yield positive results.

When the oceanography graduate student is first made aware that the permanent large-scale ocean currents are probably moving under the guidance of geostrophy, wherein the Coriolis force is balanced by a horizontal pressure gradient, the teacher is at a loss to pin down the details of the pressure gradient, except to say that there could be a sloping sea surface. That does not help in the present situation because to my knowledge no sea level data are available in the region of the wide warm surface currents, and physically how would a slope in the sea level be expected to arise in the first place?

In the future, in connection with understanding better the horizontal current shear, it may be important to explore, within the geostrophic balance and Bernoulli's law, the observed fact that the density in the surface layer should vary horizontally in the cross-stream direction due to the temperature variation associated with the observed east/west asymmetry: longitudinal SST maximum is west of the mixed layer depth maximum.

\section{CONCLUSION}

Based on observations and theory, a horizontal shear is forecast to exist in the wide warm surface currents of the North and South Pacific: the fastest in the west and the slowest in the east. Temperature observations in both oceans show that at mid-latitudes the large-scale maximum in sea surface temperature is significantly west of the region of maximum mixed layer depths. The theory involves applying Bernoulli's law along streamlines in the currents as well as the geostrophic balance of forces in the cross-stream direction.

\section{CONFLICTS OF INTEREST}

The author declares no conflicts of interest regarding the publication of this paper.

\section{REFERENCES}

1. Kenyon, K.E. (1981) A Shallow Northeastward Current in the North Pacific. Journal of Geophysical Research: Oceans, 86, 6529-6536. https://doi.org/10.1029/JC086iC07p06529

2. Kenyon, K.E. (1977) A Large-Scale Longitudinal Variation in Surface Temperature in the North Pacific. Journal of Physical Oceanography, 7, 258-263. https://doi.org/10.1175/1520-0485(1977)007<0256:ALSLVI>2.0.CO;2

3. Kenyon, K.E. (1983) Sections along $35^{\circ} \mathrm{N}$ in the Pacific. Deep Sea Research Part A. Oceanographic Research Papers, 30, 349-369. https://doi.org/10.1016/0198-0149(83)90071-7

4. Kenyon, K.E. (1978) The Surface Layer of the Eastern North Pacific in Winter. Journal of Geophysical Research: Oceans, 83, 6115-6122. https://doi.org/10.1029/JC083iC12p06115 
5. Kenyon, K.E. (1998) North Pacific High: An Hypothesis. Atmospheric Research, 51, 15-34. https://doi.org/10.1016/S0169-8095(98)00110-0

6. Fofonoff, N.P. (1960) Transport Calculations for the North Pacific. Fisheries Research Board of Canada, Manuscript Report Series.

7. Kenyon, K.E. (2012) Southward Surface Flow in the Central South Pacific. Natural Science, 4, 819-824. https://doi.org/10.4236/ns.2012.411109

8. Kenyon, K.E. (2019) Flow Past a Sphere. Natural Science, 11, 95-97. https://doi.org/10.4236/ns.2019.113010 